\title{
School nurse management of children's questions when they are involved in primary school sex education: an exploratory study
}

Hilary Piercy Faculty of Health and Wellbeing, Collegiate Crescent Campus, Sheffield Hallam University, Sheffield, UK and Mark Hayter Centre for Health and Social Care Studies and Service Development, School of Nursing \& Midwifery, University of Sheffield, Sheffield, UK

\begin{abstract}
Aim: The aim of this paper is to explore school nurses' experiences of teaching Sex and Relationships Education (SRE) as part of the primary school curriculum. In particular, it focuses on the questions that the children ask during the lessons and the strategies the nurses employ in managing those questions. Background: Schoolbased SRE is an important aspect of children's education. However, it is a highly politicised and controversial area, which is a matter of concern to a number of stakeholders. In the primary school setting, school nurses are commonly involved in delivery of the programme. Their input is particularly valued, because they are 'specialist outsiders' who create an environment that is conducive to discussion of sensitive topics. To date, there is little understanding of the skills that they employ in managing the educational needs of primary school children within the confines of a pre-agreed school curriculum. Methods: Semistructured focus group interviews were conducted with small groups of school nurses from a single geographical location in the Midlands region of England. Data were analysed using a thematic analysis approach. Findings: Data identified the ways in which the nurses viewed and responded to the children's agenda, which was realised in the form of questions. In particular, it focuses on what they deemed to be inappropriate questions and the basis on which this label was applied. Five strategies for managing these inappropriate questions were identifiable from the data. Their deployment is explored in relation to the tensions implicit in the realisation of sexualised realities in a classroom setting.
\end{abstract}

Key words: children; school nurse; sex education; sexuality

Received: April 2007; accepted: December 2007

\section{Introduction}

This paper presents findings from a qualitative study conducted in 2006, which explored school nurse experience of delivering primary school sex education. Sex and Relationships Education (SRE) is a core component of Personal, Social and Health Education (PSHE) within the school curriculum in England. Sex education lessons

Address for correspondence: Hilary Piercy, Faculty of Health and Wellbeing, Collegiate Crescent Campus, 51-53 Broomgrove Road, Sheffield Hallam University, Sheffield, S1 1 WB, UK. Email: h.piercy@shu.ac.uk constitute one place where discussion of sex and sexuality is sanctioned (Epstein and Johnson, 1998). However, their content and conduct is highly contentious and discussion is problematised. Those involved in teaching this subject must constantly walk a tightrope between endeavouring to meet the needs of the children, while staying mindful of potential ramifications such as criticism from key stakeholders and potential or actual public recrimination (Epstein and Johnson, 1998; Buston et al., 2001; Salkeld, 2007). In England, school nurses are commonly involved in classroom teaching of SRE, particularly in the primary school; however, little work 
has been done on this aspect of their role. This paper explores the ways school nurses respond to the competing interests of the children and key stakeholders through their management of the questions asked by children aged 10-12 years during these lessons.

\section{Background}

Sex education has been a target of adversarial and highly politicised debates since the 1960s (Hampshire and Lewis, 2004). At the centre of this debate is the conflict between those defending traditional moral values and those campaigning for a more pragmatic liberal sex education (Monk, 1998). Depending on the particular stance, sex education has been variously identified as a contributor or a solution to changing sexual behaviours, declining moral standards and the consequent impact on sexual health (DfEE, 2000; Hampshire and Lewis, 2004; Hampshire, 2005).

In England in recent years, a pragmatic perspective that emphasises children's rights to factual information has achieved prominence in the light of increasing concerns around the state of the nation's sexual health. The current attention on SRE can be traced back to the Teenage Pregnancy Report (SEU, 1999), which identified school-based sex education as an essential factor in achieving its ambitious target of reducing teenage conception rates by $50 \%$ in 10 years.

Arguably, SRE fulfils two functions: preparation for sexual adulthood and meeting the sexual needs of children (Monk, 1998). This first function is central to the debate as to what is taught when, especially as there is considerable variability in the physical, emotional and intellectual development within any group of children. Considerations of the second function contribute to the complexities that exist in the classroom within which learning is expected to occur; the impact of gender dynamics in relation to the conduct of lessons, the associated embarrassment and its consequent impact (Measor et al., 1996; Buston et al., 2002; Strange et al., 2003).

\section{Statutory requirements}

The statutory requirements for the provision of SRE in state schools in England are contained in the Education Act (1996) and the Learning and Skills Act (2000) and upheld in the later Education Act (2002). It is located in the curriculum for PSHE. Statutory provision of SRE is confined to secondary school education; however, it is recommended that all primary schools should have an SRE programme (DfEE, 2000).

In recent years, the content of SRE lessons has become the subject of national guidance. Detailed advice is provided on which topics should be covered at different stages of schooling (DfEE, 2000). In relation to primary school sex education, the document states that in the transition year prior to secondary school, teaching should include:

- Changes in the body related to puberty, such as periods and voice breaking.

- When these changes are likely to happen and what issues may cause young people anxiety and how they can deal with them.

- How a baby is conceived and born.

It is also expected that parents should approve the content of these lessons; the document states,

As well as consulting parents more generally about the schools overall policy, primary schools should consult with parents before the transition year about the detailed content of what will be taught.

(DfEE, 2000, p. 9)

This reflects the sensitivities and anxieties associated with this material that effectively constitutes the first foray into what is commonly regarded as sex education, that which recognises children 'as "preliminary" sexual beings, on the side of sex, yet within it' (Foucault, 1978).

\section{The role of the school nurse}

Sexual health constitutes one aspect of a school nurse's health promotional work, a core aspect of their role (Lightfoot and Bines, 2001; Croghan et al., 2003). She contributes to SRE programmes in half of all secondary schools and in one-third of all primary schools (OFSTED, 2002). Her contribution to SRE is supported by government policy (DfEE, 1999; 2000). It is valued by major stakeholders: governors, inspectors, teachers and pupils, primarily on the basis that she is 'an outsider' who can provide specialist knowledge within an 
environment that is conducive to discussing sensitive issues (Measor et al., 1999; Cotton et al., 2000; Lightfoot and Bines, 2001). Additionally, her relationship with the children will be very different from that of the class teacher; her status as an outsider has an impact that extends beyond that of a knowledgeable specialist. Her status as someone outside the school hierarchical system provides opportunity for the pupils to push against the everyday rules and boundaries. This facility, together with the socially and culturally situated gendered responses to explicit sexual information, can produce a classroom situation that is challenging and hard to manage (Measor et al., 1996). These findings derive from secondary schools where the amount of detailed information necessitates specialist knowledge. Little work has focused on SRE in the primary school. The extent to which findings from secondary schools apply to this setting where the predetermined lesson content is less sexually explicit and may therefore be less contentious is unknown.

\section{Aim}

The aim of this study was to explore school nurses' experiences of teaching SRE as part of the primary school curriculum. This paper focuses on the questions that the children ask during the lessons and the strategies, which the nurses employ in managing those questions.

\section{Methodology}

The study involved one team of school nurses employed to provide school health services in one geographical area in the Midlands region of England. Given the exploratory nature of the study, we adopted a qualitative research approach using focus groups. This naturalistic type of interview approach is particularly appropriate when participants comprise a relatively homogenous group and there is opportunity to create an open and permissive atmosphere within which participants feel able to share their own experiences and viewpoints (Morgan and Kreuger, 1993; Wilkinson, 2004). Focus groups serve as social events involving the interaction of participants and are therefore subject to social influences, for example compliance, whereby responses reflect what one believes is expected, and identification, whereby respondents align their opinions (Albrecht et al., 1993). However, the group process also has the potential to produce a synergistic effect, not only providing data on interpretation of events that reflect the group input but also a context within which unexpected insights and more elaborated accounts are produced, to a greater extent than would result from individual interviews (Frey and Fontana, 1993; Wilkinson, 2004).

All members of the nursing team $(n=24)$ were invited to participate in the study. In all, $67 \%$ of the nursing team $(n=16)$ elected to take part. Three focus groups were conducted with four to six nurses in each. Each focus group lasted approximately for $1 \mathrm{~h}$. One member of the research team (HP) facilitated all the focus groups to ensure consistency of approach, while a second member of the team served as a co-facilitator and note taker. The discussion was digitally recorded and fully transcribed with consent of the group members.

Participants were all female with a wide range of experience in school nursing (mean $=7.5$ years; range 2 months to 25 years). All had experience of delivering primary school SRE. The majority $(n=11)$ had undertaken specific sexual health training, two of whom were also registered on a recently introduced national scheme for the accreditation of PHSE teaching. A semistructured schedule of open questions was developed in consultation with a school nurse specialist. This was used to prompt the nurses to describe and discuss their experiences of teaching SRE.

This study was approved by both the Local Research Ethics Committee (LREC) and the Research Governance Committee of the Health Trust, in which the study took place.

\section{Data analysis}

Data were analysed utilising a thematic analysis approach. The method advocated by Aronson (1994) was used as a guide for data analysis. Aronson suggests initially exploring the data for segments that seem to describe a particular issue within the participant's narratives. These segments are then collated into sub-themes derived from recognition of patterns in the data. These

Primary Health Care Research \& Development 2008; 9: 75-84 
sub-themes are subsequently grouped together into larger themes providing a comprehensive picture of the collective experience (Aronson, 1994). All members of the research team initially read and re-read the transcripts. Detailed discussion between the team members led to identification of the main themes and the sub-themes situated within them. This approach ensured rigour in the data analysis process, a consideration in ensuring credibility in qualitative research (Lincoln and Guba, 1985). 'Children's questions' was one of the main themes and is the focus of this paper.

\section{Findings}

The school nurses explained that their involvement in SRE largely consisted of one or two lessons, in which they taught 11- to 12-year pupils about puberty as outlined in the SRE guidance document. Most teaching took place in mixedgender groups although the nurses also taught a girl's-only session, which dealt specifically with the practical management of menstruation.

The nurses considered that they provided opportunity for the children to ask questions of a 'knowledgeable outsider', to seek information, correct their misconceptions and fill in their knowledge gaps. They employed specific mechanisms to encourage this process. Sometimes the children were simply invited to ask questions within a session, while in other cases the nurses provided a dedicated question time, either as an adjunct at the end of a session or as a specific lesson at the end of a small programme of lessons. Sometimes this often involved the use of a question box, which effectively anonymised the process and thereby overcame the related problems of ownership and embarrassment. As one nurse explained,

I say right, while you're out at break if you've sort of got any questions that you want to ask and you don't want to put your hand up, just scribble it on a piece of paper and when you come back in from break I will have a little box on the side. Just put your questions in there and then we'll have sort of half an hour after break and I will answer the questions.

Although the children were invited and encouraged to ask any question they wanted, it

Primary Health Care Research \& Development 2008; 9: 75-84 was evident that there were restrictions on the content of questions that the nurses were willing to answer; some questions were deemed appropriate and therefore acceptable, others were not acceptable because they were considered inappropriate. The nurses identified appropriate questions as those which related specifically to the topic of the lesson and which queried aspects of puberty. However, the examples cited in the data related almost exclusively to sessions that dealt with the practical management of menstruation and the questions that were generated centred round sanitary products, details of menstruation and discharges, presumably female discharges.

Inappropriate questions and their management constituted one of the main topics of discussion in the focus groups. A number of management strategies were identified as the means by which to deal with such questions. An exploration of them provides insight into the way in which such a situation creates opportunity for the realisation of highly sexualised realities, and the containment and management strategies that are adopted to manage the inherent tensions that result from this situation.

\section{What constitutes an inappropriate question?}

Inappropriate questions were always sexual in nature; they related to specific aspects of sexual behaviour and sexual activity. They were deemed inappropriate on two counts: firstly in relation to the content of the lesson itself and secondly in relation to the needs of the other children in the class. The most common topics cited were masturbation and the purpose of condoms, particularly flavoured condoms.

And sometimes it does sort of blurb out and they do say, you know, what is masturbation miss, what is a Johnny miss, and they will ask those sorts of questions won't they?

What's a wet dream, um what's masturbation, why do you use flavoured condoms?

The children's ability to ask these questions was a product of the situation. As the purpose of the lesson was to discuss puberty, one might expect therefore that the questions that were generated would be related to aspects of puberty. However, 
using a nurse to teach this subject not only enables it to be compartmentalised, separated from maths and english, and sanctioned through the process of medicalisation but it also effectively sexualises it. When it becomes a recognised yearly ritual for the school nurse to come into school, her role in doing so becomes part of the culture of the school; the children see it as being the nurse coming in to do 'The sex talk', a recognised custom of the school. Consequently, while the school and the nurses may consider it as a puberty lesson, it is clear that the children view it differently and use the opportunity afforded to them to ask sexualised or 'inappropriate questions.'

If we're primarily going in to do a puberty talk but the kids all say, the nurse is coming to do the sex talk and as much as you try and keep it on puberty when the questions come out they do very often have very much of a sexual [nature]...

Inappropriate questions were also gender specific, being the domain of boys. As one nurse identified 'I've never had a really inappropriate question from a girl'. They were also particularly associated with the 'streetwise' child, the one who had been less protected from adult sources of information and was more knowledgeable in information and terminology that would commonly be deemed too adult for a child of his age.

There are some really purlers and they will just write anything, you know the streetwise kids will just write absolutely anything.

The nurses considered that these streetwise children were more commonly associated with specific schools and specific geographical locations, with those in more socially deprived areas more likely to produce the inappropriate question.

Obviously in different areas, different schools there's going to be a lot more streetwise children who are going to know a lot more and talk quite openly than there is necessarily another school.

\section{The management of questions}

When a child asks a question, the nurse must decide what to do with that question; whether to answer it and, if so, when and how much information to provide. In part, this was determined by the content of the question; however, other factors influenced the decision, in particular the underlying motive that they attributed to the questioner. Five strategies were identifiable in the ways the nurses dealt with the children's questions. Firstly, they provided a comprehensive answer in front of the whole group. Secondly, they dealt with it in a less direct and detailed way, throwing it back for the children to answer, effectively testing the children's knowledge levels rather than providing additional information. Thirdly, they delayed answering until a subsequent session when it was more relevant to the content of the lesson. Fourthly, they declined to answer the question in a group setting, offering the facility to answer in private after the session, an option that they admitted the children rarely took advantage of. Fifthly, they simply decided not to answer the question.

These question management decisions were influenced by what they considered to be the motives of the questioner. They recognised that the special considerations in a sex education lesson provide opportunities for children to ask questions for reasons other than a genuine request for information: to challenge or embarrass the nurse, to demonstrate their superior knowledge or to embarrass other classmates.

The two boys at the back knew what it was, they knew more than me ... it was quite obvious they knew what it was, but they'd put it in to kind of just see if I knew what it was and see if I was prepared to tell everybody else what it was. That's kind of a bit of a test I suppose wasn't it?

Notwithstanding this, for some nurses, their belief and commitment to the value of the question time placed an imperative on them to undertake to answer all questions that are posed in one way or another. As one nurse said,

I've never had a question in the box that I haven't answered in some way or other.

Even though the questions may be sexually explicit and not specifically related to the content of the lesson, there was a feeling that by asking the question, the children had earned the right to an answer.

Primary Health Care Research \& Development 2008; 9: 75-84 
I answer it because if they're asking the questions my feeling around questions, if they're asking it they need to know an answer.

For others, however, this viewpoint was tempered by other considerations; while it was acknowledged that the children's motives justified a response, nevertheless the willingness to answer a specific question was not absolute but contingent on content.

If a child asks me a question and I feel that it's appropriate then I will answer it, you know, it's... because I think that if a child, if a child is asking for a specific reason, so, you know, and I think it can be handled sensitively and openly without, without embarrassment really.

If a question relates more to content that will be covered at a later stage, there is facility for the nurse to delay answering it for the time being. This opportunity is, however, only afforded when the nurse is going into the classroom on more than one occasion and delivering a short programme of two or three sessions.

Often I will say, well this question is more appropriate to what we're going to be talking about next time so I will keep that one back if you don't mind. And that's a way that I deal with it.

When individual questions are answered in a classroom setting, the needs of all the children in the group need to be considered. This represents a considerable challenge given the wide range of age, maturity, cognitive ability and background knowledge within any one classroom. The nurses were concerned that by answering some questions, they might expose some children to detailed information for which they were not yet ready, which they did not understand. It was in these terms that some questions were deemed to be inappropriate.

I think I'm just conscious of the more immature children in the class that you know that they're finding the session probably quite hard anyway ... and I think answering some of the question would probably just tip the balance for these poor

Primary Health Care Research \& Development 2008; 9: 75-84 kids... And I just think sometimes even though that's a question that's been asked and somebody wants it answering I feel that it wouldn't be fair.

Their concerns in this respect were not confined to exposing them to such information but included consideration of the implications of doing so in respect of what they might then do with such information.

And that sometimes is where the inappropriateness comes from because they've gone out and they're inappropriately discussing in other settings because they don't really understand.

These considerations resulted in the use of other strategies, which effectively reduced the amount of information the nurse provided. One technique identified was to open the discussion and invite the children to provide answers rather than the nurse simply supplying the information. The basis of this strategy was to gauge the children's level of understanding and presumably to make an assessment on the level of information required; however, it also served as a means by which to limit the amount of information supplied by the nurse.

Sometimes you can always throw the question back. You could read the question out and say, what does anyone think, you know if it's a bit of an awkward one and you can gauge what their level of understand is then can't you?

A more assured way of protecting children in the group from what might be deemed to be too much or too explicit information was to decline to answer a question in front of the whole group. Many of the nurses explained how they would, on occasion, propose that a question be best managed by offering to answer it on a one-to-one basis at the end of the session. This was considered a means by which to best meet the needs of the whole group as well as the individual.

It's just that I tell them at the beginning that I'm willing to answer any question and if somebody asks a question that I didn't feel was appropriate to answer in front of everybody I would be still willing to answer 
it but I will suggest we answer it at the end of the session on a one to one basis. And if anybody feels too embarrassed to ask a question likewise they can come to me on a one-to-one basis.

However, it was also acknowledged as an effective means to challenge the motives of the questioner and to reduce the necessity of having to answer the question as experience indicated that the children were highly unlikely to take up this opportunity.

The fifth and final strategy employed by the nurses was to decline to answer a question, particularly if they felt that it had been put in the box to shock or challenge. The availability of an anonymised questioning format affords children the greatest freedom to ask questions by relinquishing their ownership of the questions and therefore effectively increases their opportunity to ask 'inappropriate' questions. However, such a facility also provides the nurse with the greatest freedom not to answer a question, either by ignoring its existence or by placing the onus back on the child to reclaim ownership of the question at the end of the session. As one nurse explained,

I have a question box and every child is given a bit of paper and I always say, you're to write something on it even if it's I know everything and put it in the box. And then I go through and work out which ones are appropriate and which ones aren't and always say, if I haven't answered your question in the group then hang back and I will answer it individually.

\section{Discussion}

The nurses acknowledged the children as sexual beings, with legitimate information needs and adopted an interactive teaching approach in order to meet those needs. In so doing, they created an arena within which the complex interplay of gendered sexualities was enacted. The ways in which a range of gender issues including power relations, the acquisition and use of knowledge and information, and the establishment of male hierarchies impact upon the conduct of sex education lessons with adolescents have been explored in detail (Measor et al., 1996; Buston et al., 2002; Strange et al., 2003; Alldred and David, 2007). For some children, these processes are highly inhibitory, preventing them from voicing their questions and concerns. Question boxes redress the impact of such processes and support the needs of all children; however, the lack of ownership necessarily limits opportunities for further questioning and clarification.

This approach also provides facility for the children to ask 'inappropriate' questions. Answering these questions is problematic. The classroom is a public arena subject to considerable surveillance and sanction (Cumper, 2006). Providing information in response to questions that transgress the implicit boundaries of acceptability has potential ramifications. In order to manage the situation and remain within these boundaries, the nurses employ techniques that effectively comprise alternative ways of limiting the supply of information. To what extent this meets the needs of the more sexualised children is questionable; notwithstanding the children's motives, inviting questions and then not answering them not only fails to address the information needs of those asking the questions but also harbours resentment and frustration (Measor et al., 2000).

A more fundamental question is the categorisation of inappropriate; why girls' questions about menstruation and female discharges were appropriate, while boys' questions about 'wet dreams' were inappropriate, although both are linked with pubescence and therefore contextually relevant to the session. Gender differences in the teaching of puberty have been the focus of critique, in particular the problematisation of female puberty. Factual information is largely confined to the reproductive process while menstruation is conceptualised as troublesome with an emphasis on the individual management of this change and its associated personal and social hygiene problems (Diorio and Munro, 2000). The girls' questions that arise from and pertain to this are unproblematic and are therefore considered appropriate by the nurses. By contrast, teaching of male pubertal development recognises, at least potentially, sexual pleasure and power in the form of 'wet dreams' and 'ejaculation' (Fine, 1988; Diorio and Munro, 2000). Such questions are difficult to answer because they potentiate discussions that recognise and acknowledge sexual pleasure and desire. Consequently, they are

Primary Health Care Research \& Development 2008; 9: 75-84 
deemed 'inappropriate' and management strategies are deployed.

Condoms, and especially flavoured condoms, were a particular source of anxiety for the nurses and necessitated deflection techniques. These findings resonate with those of Measor et al. (2000), whose work with secondary school children similarly reports children's tendency to ask these questions and educators resistance to answering them. It is evident from children's accounts that by 9-10 years, many of them are aware of the existence of condoms, their purpose and the fact that they come in a variety of flavours (Halstead and Waite, 2002; Piercy and Haynes, 2006). These questions are therefore unsurprising; children exist in a highly sexualised world, which is saturated with sexual imagery, and given the opportunity and permission to do so, they ask questions of a sexual nature (Halstead and Waite, 2002). The facilitative environment created by the nurses and the medicalisation of SRE through the use of health professionals effectively sanctions condoms, the epitome of sexually responsible behaviour within a health promotion discourse, as a valid topic of discussion. However, while simple condom questions may be contained and managed through explanations of safety and responsibility, answering questions about flavoured condoms constitutes a much greater problem. Flavoured condoms are the visible realisation of efforts to increase usage by reframing protected sexual intercourse in terms of sexual pleasure rather than risk and responsibility (Venis, 2005; Edouard, 2006). A persistent criticism of classroom SRE, particularly by young people, is the emphasis placed upon factual and physiological detail and the failure to acknowledge and endorse sexual desire and satisfaction (Fine, 1988; Epstein and Johnson, 1998; Diorio and Munro, 2000; Buston et al., 2002; Strange et al., 2003; Hirst, 2004). It is problematic to address this topic in the classroom because it requires some acknowledgement of explicit sexual activity and sexual pleasure. However, children appear as likely to raise questions of this type in the primary setting as they are in secondary schools.

Stemming from the corruption discourse that blames sex education for promoting sexual activity, anxieties about age-appropriate information are a recurring theme in relation to school-based SRE and provide the basis for information deflection techniques (Alldred and David, 2007). If these children's questions reflect their efforts to make sense of the highly sexualised world in which they live, we need to question whether these techniques enable them to do so. The recent OFSTED report (2007) identified a lack of clear agreement on the boundaries of acceptability in terms of SRE content. The question arising from this is who determines that acceptability and to what extent the children's need for information are taken into account in such considerations?

\section{Conclusion}

Involving school nurses in the teaching of primary school SRE appears to provide opportunity and license for children to present a sexualised agenda. While some questions may stem from motives other than a quest for knowledge, children are becoming sexually aware at an earlier age and appear to have information needs that are highly challenging to manage in a classroom situation. They commonly introduce topics deemed unsuitable for explanation. The nurses, mindful of the sensitivities of the key stakeholders, deploy a number of identifiable strategies in order to restrict the information provided.

It is important to acknowledge the skills and experience required for the nurses undertaking this role. Ongoing professional support and specialist sexual health training are essential in relation to this. In this context, explicit acknowledgement of the pre-existing boundaries, their basis and the means by which they are maintained would be helpful in order to support their practice, improve their confidence and competence, and thereby enable them to better meet the information needs of the children. This is particularly relevant when considering the needs of those embarking on this kind of work for the first time.

The structure and conduct of the nurses' lessons provide them with considerable insight into children's agendas around sexual knowledge. The role of SRE is to support children in making sense of a highly sexualised world. In this area, where children's voices are rarely heard, the nurses are well placed to serve as advocates negotiating for their information needs. However, in order to do so 
they need to be fully involved in ongoing debates about what constitutes acceptable and age-appropriate information at a number of levels: from local school level to national debate informing educational policy. In individual schools, it is essential that nurses' involvement is not confined to classroom delivery but includes involvement in SRE planning and policy determination.

\section{Acknowledgements}

With thanks to Marie-Therese Massey and Trudy Gregory who assisted with the research, to the study participants and to the manager of the school nursing service whose support was essential for this study.

\section{References}

Albrecht, T., Johnson, G. and Walther, J. 1993: Understanding communication processes in focus groups. In Morgan, D., editor, Successful focus groups: advancing the state of the art. Newbury Park: Sage Publications, 51-64.

Alldred, P. and David, M. 2007: Get real about sex: the politics and practice of sex education. Maidenhead: Open University Press.

Aronson, J. 1994: A pragmatic view of thematic analysis. The qualitative report 2(1): Spring. Retrieved August 2006, from http://www.nova.edu/ssss/QR/BackIssues/QR2-1/ aronson.html

Buston, K., Wight, D. and Hart, G. 2002: Inside the sex education classroom: the importance of context in engaging pupils. Culture, Health and Sexuality 4, 317-35.

Buston, K., Wight, D. and Scott, S. 2001: Difficulty and diversity: the context and practice of sex education. British Journal of Sociology of Education 22, 353-68.

Cotton, L., Brazier, J., Hall, D., Lindsay, G., Marsh, P., Polnay, L. and Wiliams, T. 2000: School nursing: costs and benefits. Journal of Advanced Nursing 31, 1063-071.

Croghan, E., Johnson, C. and Aveyard, P. 2003: School nurses: policies, working practices, roles and value perceptions. Journal of Advanced Nursing 47, 377-85.

Cumper, P. 2006: Let's talk about sex: balancing children's rights and parental responsibilities. Legal Studies 26, 88-108.

DfEE. 1996: Education Act. London: HMSO.

DfEE. 1999: National healthy school standard: sex and relationship education. London: Department for Education and Employment, HMSO.

DfEE. 2000: Sex and Relationship Education Guidance. London: Department for Education and Employment.

DfEE. 2000: Learning and Skills Act. London: HMSO.

DfEE. 2002: Education Act. London: HMSO.
Diorio, J. and Munro, J. 2000: Doing harm in the name of protection: menstruation as a topic for sex education. Gender and Education 12, 347-65.

Edouard, L. 2006: In condoms we trust; to each, one's own. Journal of Family Planning and Reproductive Health Care 32, 262-64.

Epstein, D. and Johnson, R. 1998: Schooling sexualities. Buckingham: Open University Press.

Fine, M. 1988: Sexuality, schooling and adolescent females: the missing discourse of desire. Harvard Educational Review $58,29-53$.

Foucault, M. 1978: The will to knowledge. The history of sexuality: 1. London: Penguin Books.

Frey, J. and Fontana, A. 1993: The group interview in social research. In Morgan, D., editor, Successful focus groups: advancing the state of the art. Newbury Park: Sage Publications, 20-34.

Halstead, M. and Waite, S. 2002: Worlds apart: the sexual values of boys and girls. Education and Health 20, 17-23.

Hampshire, J. 2005: The politics of School Sex Education Policy in England and Wales from the 1940s to the 1960s. Social History of Medicine 18, 87-105.

Hampshire, J. and Lewis, J. 2004: 'The ravages of permissiveness': sex education and the permissive society. Twentieth Century British History 15, 290-312.

Hirst, J. 2004: Researching young people's sexuality and learning about sex; experience, need and sex and relationship education. Culture, Health and Sexuality 6, 115-29.

Lightfoot, J. and Bines, W. 2001: Working to keep school children healthy: the complementary roles of school staff and school nurses. Journal of Public Health Medicine 22, 74-80.

Lincoln, Y.S. and Guba, E. 1985: Naturalistic inquiry. California: Sage Publications.

Measor, L., Tiffin, C. and Fry, K. 1996: Gender and sex education: a study of adolescent responses. Gender and Education 8, 275-88.

Measor, L., Tiffin, C. and Miller, K. 1999: The impact of health professionals' involvement in sex education in schools. Nursing Times Research 4, 386-93.

Measor, L., Tiffin, C. and Miller, K. 2000: Young people's views on sex education. London: Routledge/Falmer.

Monk, D. 1998: Sex education and HIV/AIDS: political conflict and legal resolution. Children and Society 12, 295-305.

Morgan, D. and Kreuger, R. 1993: When to use focus groups and why. In Morgan, D., editor, Successful focus groups: advancing the state of the art. Newbury Park: Sage Publications, 3-19.

OFSTED. 2002: Sex and relationships. London: HMI.

OFSTED. 2007: Time for change? Personal, social and health education. London: HMI.

Piercy, H. and Haynes, G. 2006: Coherent, comprehensive and continuous: developing a curriculum for effective sex and relationship education in an English primary school. Education and Health 24, 12-15.

Primary Health Care Research \& Development 2008; 9: 75-84 
Salkeld, L. 2007: Outcry over explicit sex education video shown to five-year-olds. Daily Mail. 26th February.

SEU. 1999: Teenage pregnancy report. London: Social Exclusion Unit.

Strange, V., Oakley, A. and Forrest, S. 2003: Mixed-sex or single-sex sex education: how would young people like their sex education and why. Gender and Education 15, 201-14.

Venis, S. 2005: Lunch with the Lancet - Sarah Philpott. Lancet $365,565$.

Wilkinson, S. 2004: Focus group research. In Silverman, D., editor, Qualitative research: theory, method and practice. London: Sage Publications, 177-199. 